\title{
Development of a radiative heating facility for studying flow and heat transfer in hydrocarbon-cooled structures
}

Cite as: Rev. Sci. Instrum. 89, 064901 (2018); https://doi.org/10.1063/1.5018243

Submitted: 05 December 2017 . Accepted: 24 May 2018 . Published Online: 12 June 2018

Da Dong, Yang Lu, Yueming Yuan, and Xuejun Fan
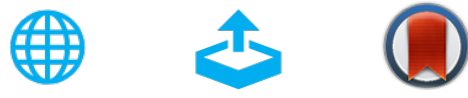

View Online

Export Citation

\section{ARTICLES YOU MAY BE INTERESTED IN}

Feedback control of local hotspot temperature using resistive on-substrate nanoheater/ thermometer

Review of Scientific Instruments 89, 064902 (2018); https://doi.org/10.1063/1.5020884

An enhanced broad-frequency-band apparatus for dynamic measurement of elastic moduli and Poisson's ratio of rock samples

Review of Scientific Instruments 89, 064503 (2018); https://doi.org/10.1063/1.5018152

Ultra-broadband coplanar waveguide for optically detected magnetic resonance of nitrogen-vacancy centers in diamond

Review of Scientific Instruments 89, 064705 (2018); https://doi.org/10.1063/1.5028335

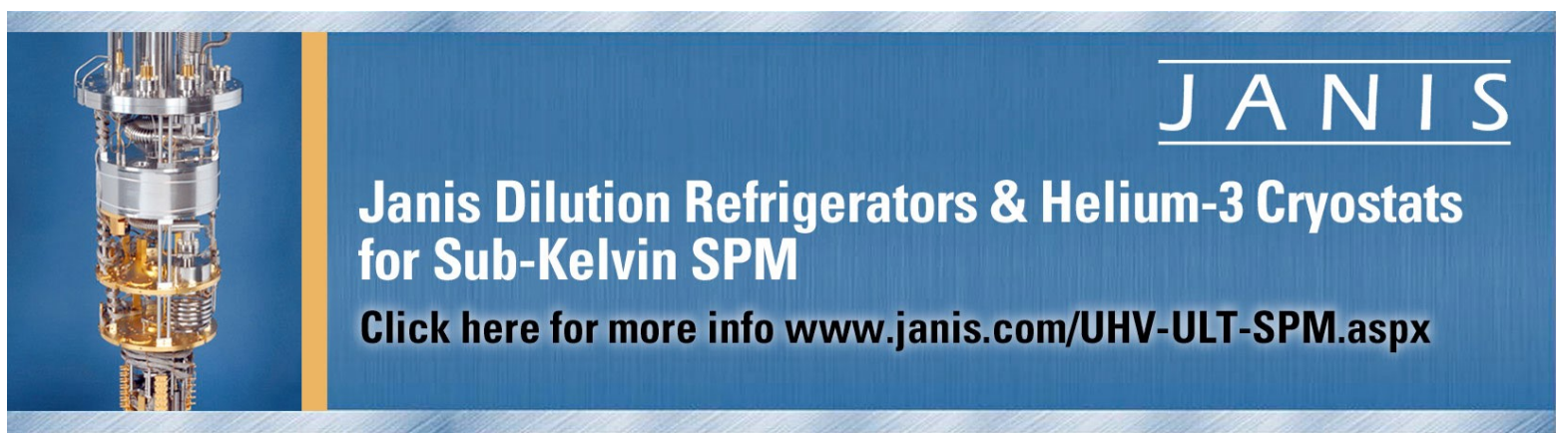




\title{
Development of a radiative heating facility for studying flow and heat transfer in hydrocarbon-cooled structures
}

\author{
Da Dong, ${ }^{\text {a) }}$ Yang Lu, ${ }^{\text {b) }}$ Yueming Yuan, and Xuejun Fanc) \\ LHD, Institute of Mechanics, Chinese Academy of Sciences, Beijing 100190, People's Republic of China \\ and School of Engineering Science, University of Chinese Academy of Sciences, Beijing 100049, \\ People's Republic of China
}

(Received 5 December 2017; accepted 24 May 2018; published online 12 June 2018)

\begin{abstract}
An experimental facility was designed to simulate the heat exchange between the hot gas and the fuel-cooled wall in a scramjet combustor. Thermal radiation from an electrically heated graphite plate is employed to unilaterally heat up a multi-channeled cooling plate. A maximum heat flux of over $0.8 \mathrm{MW} / \mathrm{m}^{2}$ was achieved for an effective heating area up to $1000 \mathrm{~mm} \times 40 \mathrm{~mm}$. Precise control of the back pressure of a coolant (up to $5 \mathrm{MPa}$ ) in a unique way was also demonstrated. With this facility, studies of flow and heat transfer in hydrocarbon-cooled structures can be performed under a well-controlled manner. Published by AIP Publishing. https://doi.org/10.1063/1.5018243
\end{abstract}

\section{INTRODUCTION}

Regenerative cooling is used as an effective thermalmanagement solution in various high-speed vehicle engines, ranging from rocket, ${ }^{1}$ ramjet/scramjet ${ }^{2}$ to many other combined cycle applications. ${ }^{3}$ Storable or cryogenic hydrocarbons ${ }^{4}$ are often chosen as the propellant/coolant to fuel and cool down the combustion chambers simultaneously. Before injected into the combustor, the coolant fuel is forced through the mini-channels embedded in the combustor wall to absorb heat and cool down the combustion chamber. As the heat from the chamber is not wasted overboard but recycled into the combustor instead, this process is called "regeneration." During the process, the coolant temperature can increase considerably, which will benefit atomization, mixing, and subsequent combustion. ${ }^{5}$ However, the flow and heat transfer characteristics of industrial hydrocarbon fuels, which always consist of many species, are quite complicated due to the rapid changes in fuel states and their thermo-physical properties. In the near-thermodynamic-critical-pressure region, the heat transfer deterioration may be encountered, together with the instability and change in the pressure drop. ${ }^{6}$ Although the pressure of hydrocarbon under typical working conditions can exceed the critical value, the margin is often limited due to the available pumping power. Therefore, undesired instability and change in the pressure drop will introduce design uncertainties or practical usage problems (for example, as the engine starts, it is inevitable that it will take some time for the pressure to cross the critical region and reach its final supercritical value). Additionally, when the temperature of the coolant is raised up to near the critical point or near the crack temperature region, instability ${ }^{7-9}$ may also happen even at high pressures above the critical values and bring potential unaffordable risks for the thermal management. Moreover, the problem may be

\footnotetext{
a)dongda12@mails.ucas.ac.cn

b) Author to whom correspondence should be addressed: luyang@imech.ac.cn c) xfan@imech.ac.cn
}

further complicated when parallel channels,${ }^{10}$ rather than single channel arrangement, ${ }^{11}$ are considered. Unfortunately, as admitted by researchers, ${ }^{6}$ the heat transfer and pressure drop in the critical region remains an elusive problem. The effects of various factors such as heat flux, mass flux, pressure levels, and channel geometry in such regions merit systematic investigation.

In most former studies, ${ }^{6-9,11}$ a metal tube heated by the electricity was employed to simulate the cooling channel inside the combustor wall. Although single-tube experiments have achieved understandings in characteristics of convective heat transfer $^{6}$ and hydro-instability ${ }^{9}$ of jet fuels in mini-channels, there were still two deficiencies: (1) They fail to present the distribution of temperature on the combustor wall, and (2) the fuel flow rate redistribution between different channels in the combustor wall is obviously missed in the single-tube configuration. Therefore, the characteristics of heat transfer in realistic hydrocarbon-cooled combustors cannot be faithfully presented by the single-tube experiments. In this regard, a benchmark test facility is needed, which enables low cost (comparing with experiments using actual combustors), long duration experimental studies for the hydrocarbons with controllable boundary conditions (adjustable heat flux, mass flow rate, and pressure levels of a wide range). Such a device should embody essential characteristics of a regenerative-cooled combustor featuring unilateral heating of multi-channeled cooling plates. To the authors' knowledge, Sillence ${ }^{12}$ reported a similar test rig as a small part of his experimental project, while the details of its working capability were not available. However, in their facility layout, quartz lamps were employed to heat up the test panel in an open space which obviously limited its maximum heat flux.

In this study, a new facility was designed and realized to simulate the thermal environment between the hot inner flow and the actively cooled wall in a combustion chamber. Controllable thermal radiation from an electrically heated graphite plate is projected onto a cooling plate, through which the kerosene flows while absorbing heat. Moreover, a unique way 


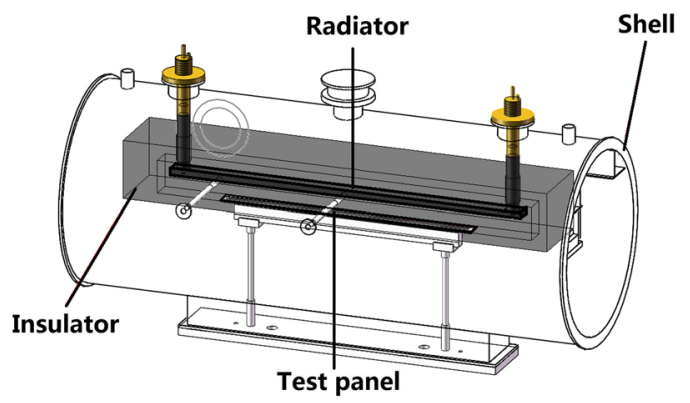

FIG. 1. Sketch of the mainstay of the facility.

for precise control of the back pressure of a coolant was also demonstrated. With this test platform, the flow and heat transfer studies on the hydrocarbons with the structures of different materials and various configurations were performed under a wide range of heat flux and pressure levels.

\section{DESCRIPTION OF THE FACILITY}

The design here mainly draws on radiation to provide high heat flux and bases on Stefan-Boltzmann's Law

$$
j^{*}=\varepsilon \sigma T^{4},
$$

where $\sigma=5.67 \times 10^{-8} \mathrm{~W} /\left(\mathrm{m}^{2} \mathrm{~K}^{4}\right)$ and $\varepsilon$ is the surface emissivity. Graphite is selected as the material of the radiator for its high electric conductivity and good mechanical properties at high temperatures. As shown in Fig. 1, the radiator and the test panel are installed in parallel and surrounded by the insulator, while all of them are fixed in the shell that can be evacuated. Those four parts constitute the mainstay of the facility. Besides, there are several subsystems for coolant supply, power supply, and data acquisition.

\section{A. The mainstay of the facility}

A graphite plate was chosen to be the radiator. It is jointed with two graphite cylinders. Mortise-tenon joints (Fig. 2) are used at both ends of the graphite plate. For each tenon, there are gaps on both sides so that the graphite plate can slide when it is heated and expands. Two graphite bolts lifting the plate are screwed into the cylinders. The bolts must be adjusted neither too loose to provide enough contact area between the plate and the cylinders for electric conduction nor too tight to allow the plate sliding. Besides, those bolts are intensified

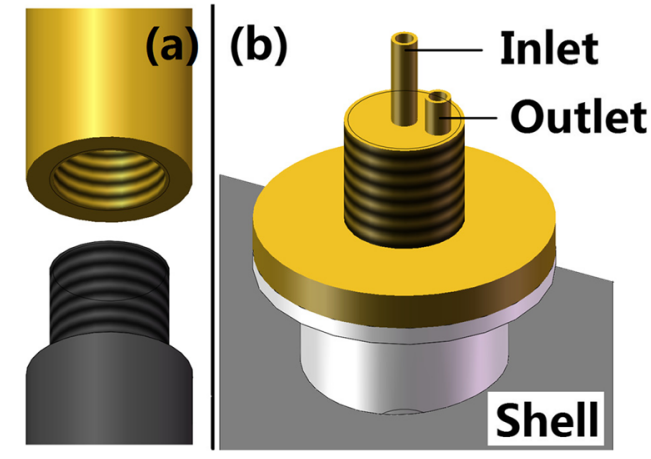

FIG. 3. (a) Joint of the graphite cylinder and the brass flange. (b) The brass flange.

with carbon fiber so that they have enough tensile strength to confront expansion of the plate in the vertical direction.

The thread on the top of the graphite cylinders connects them to two brass flanges (Fig. 3) which are fixed on the shell. In this way, the radiator is placed firm and electric power can be accessed. The flanges have interlayer for cooling with distilled water. Seal rings in the flanges are coated with vacuum grease for good air impermeability. The bolts fastening the flanges are equipped with ceramic casing pipes so that the flanges are well insulated from the shell.

The test panel is placed parallel to the radiator, fixed on two stacked upholders (Fig. 4). One upholder next to the panel is made of a $\mathrm{C} / \mathrm{C}$ composite material for thermal insulation. The other one is made of steel for enough strength to support the panel. All of them are bonded by five long screws to prevent thermal deformation of the panel at high temperatures. The entirety of those three parts is placed on the top of two steel sticks, which are welded to the shell and ensure the test panel is aligned with the graphite plate. Two pipes with spherical joints are used for connecting the panel to the outside coolant circulation through two orifices, which are located on the bottom of the shell (Fig. 5).

The insulator (Fig. 6) is made of porous graphite felt which has thermal conductivity of only $0.3 \mathrm{~W} /(\mathrm{m} \mathrm{K})$. Graphite plates cover the whole inside surface of the felt. Besides, three layers of graphite plates are embedded in the felt at regular intervals. They can shield thermal radiation effectively at high temperatures for the felt is partially transparent for thermal radiation. In this way, thermal radiation is gathered onto the heated

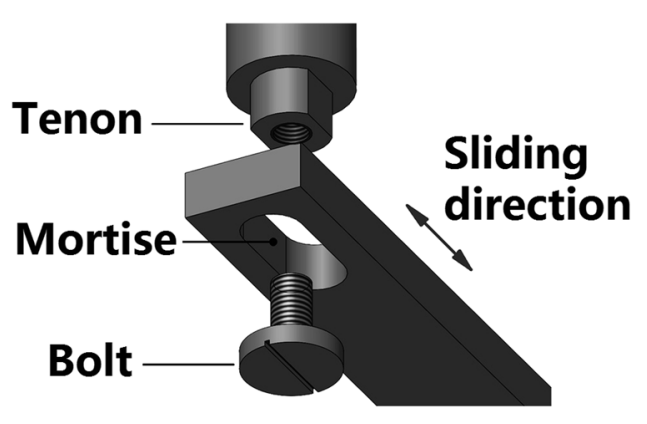

FIG. 2. Joint between the graphite plate and the cylinder.

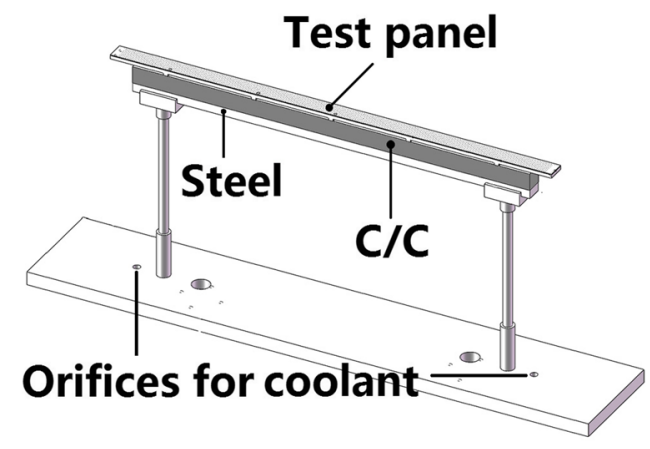

FIG. 4. Installation of the test panel. 


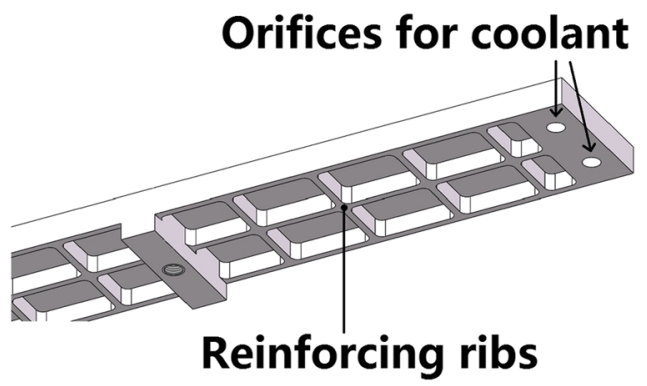

FIG. 5. Outer structure of the test panel.

surface of the test panel in order to achieve conditions of high heat flux. The felt and the plates are bonded by graphite screws and fixed in a steel frame which is placed in the shell. There are two orifices on the top and a rectangular slot on the bottom of the insulator. The graphite cylinders, which are connected to the radiator, pass through the orifices with no contact to keep electric insulation. The test panel is placed in the slot slightly adjoining the felt around it.

The shell (Fig. 6) is a hollow cylinder made of stainless steel. Two hemispherical doors (omitted in the figure) are located at both ends of the cylinder, and a rectangular plate seals up the bottom. Both the cylinder and the hemispherical doors have an interlayer for cooling. A vacuum pump is connected to the shell through metal bellows. Air in the shell is evacuated to prevent the oxidation of the graphite as well as the natural convection, which influences the accuracy of the radiative heat flux. Generally, the pressure in the shell is set about $10 \mathrm{~Pa}$ before each experiment.

\section{B. Coolant supply and pneumatic control system}

Various hydrocarbon fuels and test panels with different designs can be studied in this facility under a wide range of conditions. In this study, China RP-3 kerosene is used as the coolant. Panels made of stainless steel or super alloy are equipped accordingly. Those panels have mini-channels of different geometric configurations. Figure 7 shows the inner structure of a typical test panel.

As shown in Fig. 8, the kerosene is circulated by a plunger pump with a frequency converter. The mass flow rate of kerosene (M) changes along with the plunger pump's revolving speed, which is determined by the set value of the frequency. One of the characteristics of plunger pump is that volumetric efficiency decreases as pressure rises. That means while the pressure of kerosene goes up, the mass flow rate will

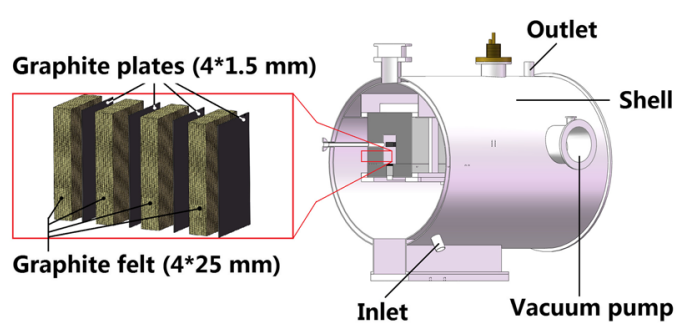

FIG. 6. Inner Structure of the mainstay of the facility.

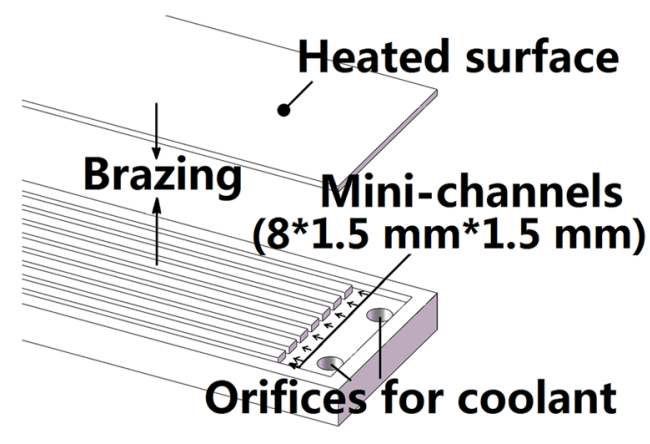

FIG. 7. Inner structure of the test panel.

reduce even if the frequency of the pump is fixed. Hence, a PID (Proportion Integration Differentiation) feedback control is introduced to keep the mass flow rate consistent with the set value. Furthermore, if a sudden considerable decrease appears in the mass flow rate, which is caused by flow instability in some cases, the feedback control can bring the flow rate back and prevent overheating of the test panel. After all, temperature of the radiator cannot reduce immediately due to heat preservation of the insulator after the electric power is shut down.

Nitrogen is provided to the coolant circulation at the downstream of the test panel. The pressure of the nitrogen flow can be set conveniently by a pressure regulator. By doing this, the outlet pressure of the coolant (often as same as pressure before injection) can be adjusted as needed precisely. It is a very attractive characteristic as combustor design always requires nailing down of the chamber pressure value. The mixture of the nitrogen and the heated kerosene passes through the condenser, where its temperature drops down and gets close to the room temperature. After that, a gas-liquid separator segregates the nitrogen and discharges it to the atmosphere. Meanwhile, the kerosene flows back to the tank. In the cases that kerosene has partially cracked in the test panel, the products are gathered by a collection device instead.

Nitrogen is also introduced as a medium for pneumatic control. There are two groups of pneumatic valves in the coolant circulation. One group (V3 and V5) is located at the inlet of the test panel for selective kerosene delivery. Kerosene of room temperature comes from the plunger pump

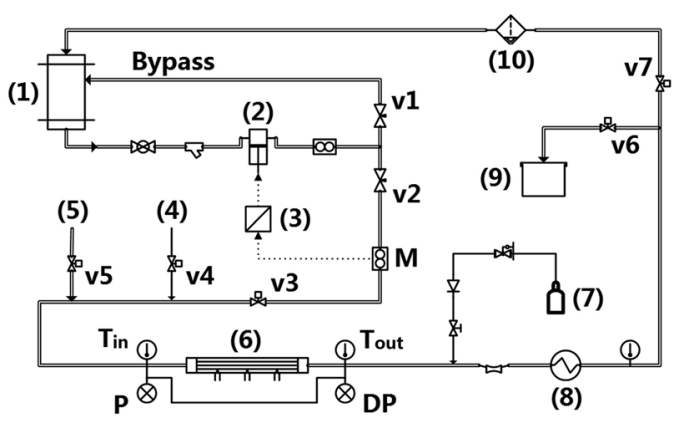

FIG. 8. Coolant circulation: (1) tank, (2) plunger pump, (3) frequency converter, (4) nitrogen/air for cleanout, (5) two-stage kerosene-heating system, (6) test panel, (7) nitrogen for pressure control, (8) condenser, (9) collection device for cracked kerosene, and (10) gas-liquid separator. 


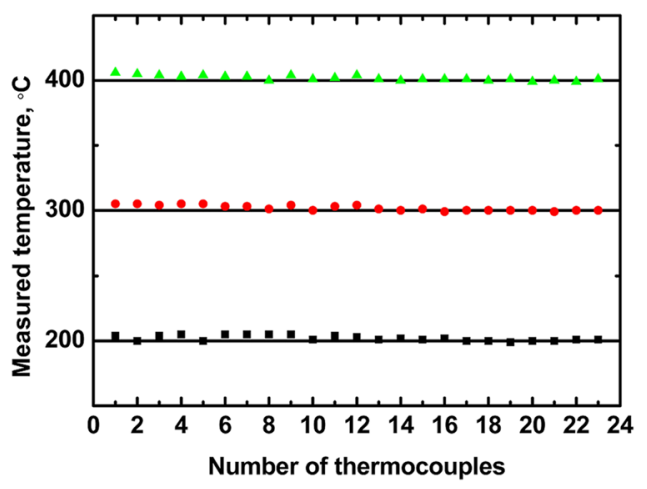

FIG. 9. Result of the thermocouples' calibration.

directly, while that of higher specific temperatures can be supplied by a two-stage kerosene-heating system. ${ }^{13}$ In this way, effects of different inlet temperatures can be studied. The other group (V6 and V7) controls collection of heated kerosene abovementioned.

\section{Power supply and cooling of the facility}

Electric power which is provided by a silicon controlled rectifier sustains the radiator. The rectifier transforms threephase $\mathrm{AC}$ to $\mathrm{DC}$ of a low voltage and high current to ensure safety of operators. The power it outputs can be regulated either manually or automatically. In the automatic mode, an infrared thermometer measures temperature of the radiator and transfers it to the power controller. Then the measured temperature is compared to the set value, and power output can be adjusted by the PID method.

The thermometer is placed outside the shell aiming at the radiator. There are two glass windows aligned at the middle and the end of the radiator, respectively. In this way, homogeneity of the temperature can be examined when the radiator is working. Passing through the insulator, two graphite pipes lie between the inspection windows and the radiator so that bias light from the shell can be shielded.

For the sake of electric insulation, distilled water is used for cooling of the rectifier as well as the brass flanges abovementioned. On the other hand, the shell and the vacuum pump are cooled by ordinary water. The coolant which absorbs heat in the test panel needs to be cooled in the condenser, too. In consideration of extreme cases, such as failure of the insulator, circulation of ordinary water provides enough heat capacity to absorb all the heat generated by the radiator.

\section{Data acquisition system}

Several K-type thermocouples are welded on the unheated surface of the test panel in order to measure the wall temperatures. It is necessary to connect the thermocouples, which are in the evacuated shell, to the outside computer. A specially designed flange is used for leading the thermocouples out directly so that there is no third kind of metal existing in the circuit. In this way, accuracy of the measurement can be ensured, even if the temperature distribution along the circuit varies dramatically. Besides, the flange has good air impermeability.

Two sheathed K-type thermocouples are placed at the inlet and the outlet of the test panel, respectively, in order to measure the bulk temperatures of the coolant.

Those thermocouples were calibrated by the CST6001 temperature calibrator under temperatures of 200,300, and $400{ }^{\circ} \mathrm{C}$, as shown in Fig. 9.

All the signals which are transduced by the sensors are amplified before being imported into the computer. A NI PCI6225 unit receives those signals, and then, a program based on LabVIEW records the data. Generally, the sampling frequency is $20 \mathrm{~Hz}$. Specification of the sensors is shown in Table I.

Figure 10 shows photos of the subsystems of the facility.

\section{MEASUREMENT AND CONTROL IN THE FACILITY}

\section{A. Temperature of the radiator}

Two indicators of the radiator's performance are stability and homogeneity of its temperature. Figures 11 and 12 show typical patterns of the heating process. In case A, the measured temperature reached $1350{ }^{\circ} \mathrm{C}$ and then $1450{ }^{\circ} \mathrm{C}$, while in case $\mathrm{B}$, it went up to $1550{ }^{\circ} \mathrm{C}$ directly. Different experiments were conducted where the temperature was hold constant or changed. When the power supply and the mass flow rate of the coolant are locked, temperature of each part in the shell will not change conspicuously. Once the flow and heat transfer become steady, the infrared thermometer is allowable to move from one inspection window to the other. In this way, temperatures at the end of the radiator can be measured. The result in case A showed that it $\left(1379^{\circ} \mathrm{C}\right)$ was $2 \%$ higher than the temperature in the middle $\left(1353{ }^{\circ} \mathrm{C}\right)$. Considering the distance between the two inspection windows which is $500 \mathrm{~mm}$, the temperature homogeneity is satisfactory.

\section{B. Heat flux on the test panel}

What really matters is the value and distribution of the heat flux received by the test panel. In steady state, the average heat

TABLE I. Specification of the sensors.

\begin{tabular}{lccl}
\hline \hline Apparatuses & Ranges & Accuracy $(\%)^{\mathrm{a}}$ & Model \\
\hline Infrared thermometer $\left({ }^{\circ} \mathrm{C}\right)$ & $750-3000$ & \pm 0.3 & IRCON MODLINE 52-3042 \\
Coriolis mass flow meter $(\mathrm{g} / \mathrm{s})$ & $0-100 / 0-250$ & \pm 0.1 & SINCERITY DMF-1/-3B \\
K-type thermocouple $\left({ }^{\circ} \mathrm{C}\right)$ & $0-1300$ & \pm 0.75 & OMEGA \\
Pressure transducer $(\mathrm{MPa})$ & $0-10$ & \pm 0.25 & WSTZH \\
Differential pressure transducer $(\mathrm{kPa})$ & $0-120 / 0-500$ & \pm 0.25 & WSTZH \\
\hline \hline
\end{tabular}

${ }^{\mathrm{a}}$ From respective manufacturer datasheets. 


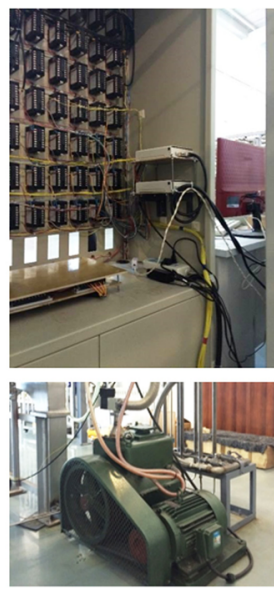

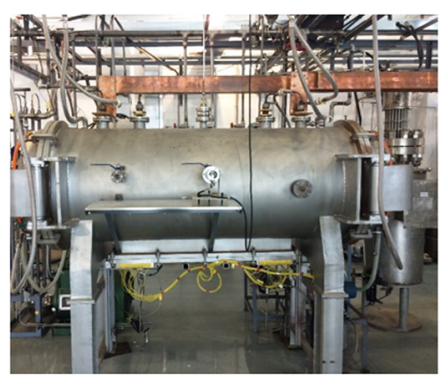

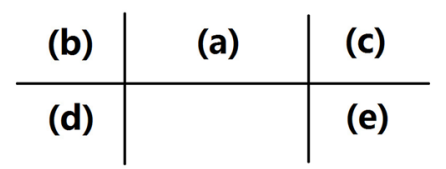

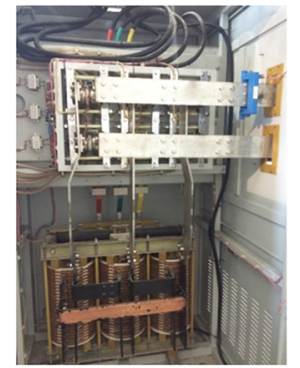

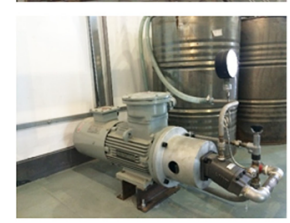

FIG. 10. Photos of the facility: (a) mainstay of the facility, (b) data acquisition system, (c) power supply, (d) vacuum pump, and (e) plunger pump. flux can be calculated by measuring total heat absorbed by the coolant,

$$
Q_{a}=\dot{m} \bar{C}_{p}\left(T_{\text {out }}-T_{\text {in }}\right),
$$

where $\dot{m}$ is mass flow rate and $\bar{C}_{p}$ is average specific heat at constant pressure. For instance, temperature of the radiator was $1550{ }^{\circ} \mathrm{C}$, and the kerosene's mass flow rate was $80 \mathrm{~g} / \mathrm{s}$; the outlet temperature went up to $243^{\circ} \mathrm{C}$ (with an inlet temperature of $37^{\circ} \mathrm{C}$ ). The average specific heat can be ascertained by table look-up: $\bar{C}_{p}=2.05 \mathrm{~kJ} /(\mathrm{kg} \mathrm{K})$. Then the total heat is

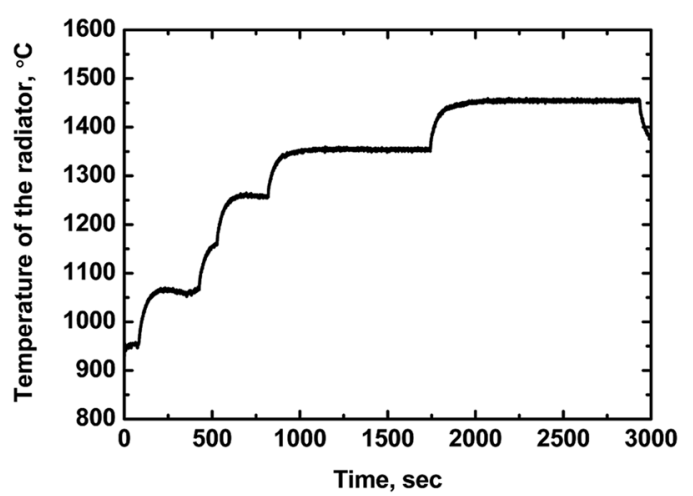

FIG. 11. Time history of the temperature of radiator (case A).

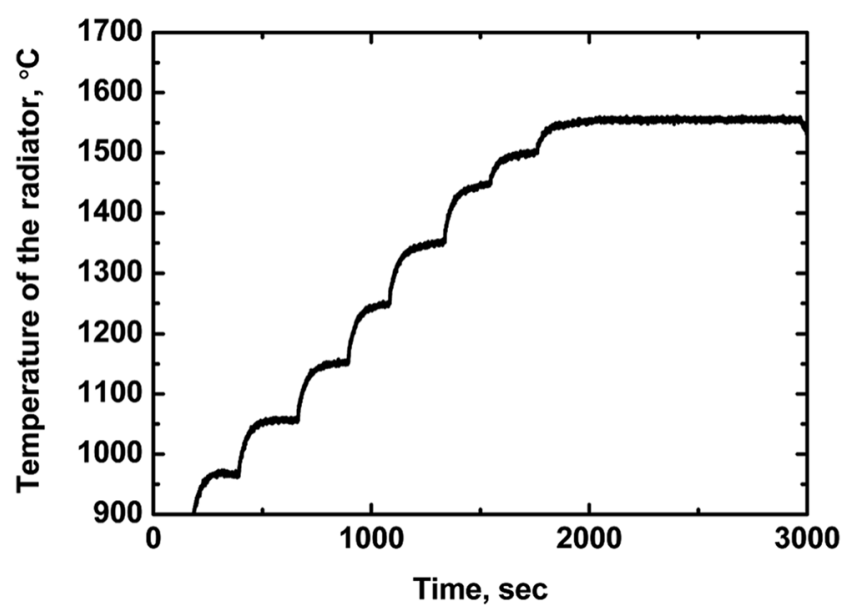

FIG. 12. Time history of the temperature of radiator (case B).
$Q_{a}=33784 \mathrm{~W}$, which corresponds to an average heat flux of $844.6 \mathrm{~kW} / \mathrm{m}^{2}$ with the heated area of $0.04 \mathrm{~m}^{2}$. In this case, the mass flow rate of kerosene was set much larger than those in working conditions so that the outlet temperature was in the region where the specific heat could be measured accurately.

Since temperature on the outside surface of the insulator remains under $400{ }^{\circ} \mathrm{C}$ and its area is $2.22 \mathrm{~m}^{2}$, thermal radiation it emits (heat loss) in steady state has a theoretical maximum of $24803 \mathrm{~W}$ (no influential natural convection existing in the evacuated shell). Hence, the net heat flux passing through the inside surface of the insulator $\left(0.6 \mathrm{~m}^{2}\right)$ is $40.7 \mathrm{~kW} / \mathrm{m}^{2}$. Meanwhile, the heat flux projected on the inside surface of the insulator from the radiator is $626 \mathrm{~kW} / \mathrm{m}^{2}$. The result indicates that less than $7 \%$ of the heat flux projected on the inside surface of the insulator passes through it. The rest is either reflected back or absorbed by the graphite plates and then emitted back to the cavity. In either case, the insulator guarantees high heat flux which the test panel needs. However, to calculate heat transfer between the radiator and the test panel directly is complicated because the inside surface of the insulator redistributes the thermal radiation in the cavity.

Simulation in a computer program was performed to get specific distribution of the heat flux on the test panel. It is a reasonable approximation that all the surfaces in the cavity are diffuse gray surfaces, which means the radiation they emit and reflect is independent of direction and wavelength. Besides, the surfaces are non-transparent. Distribution of temperature on the surfaces of the radiator and the test panel was set as measured in experiments. Figure 13 shows the result which

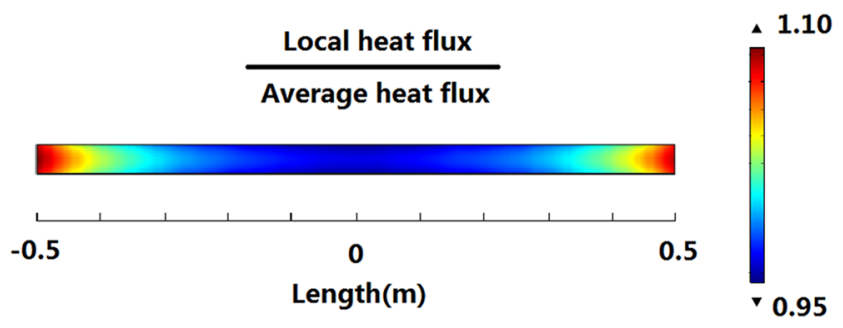

FIG. 13. Dimensionless heat flux distribution on the test panel of $1000 \mathrm{~mm}$ $\times 40 \mathrm{~mm}$. 


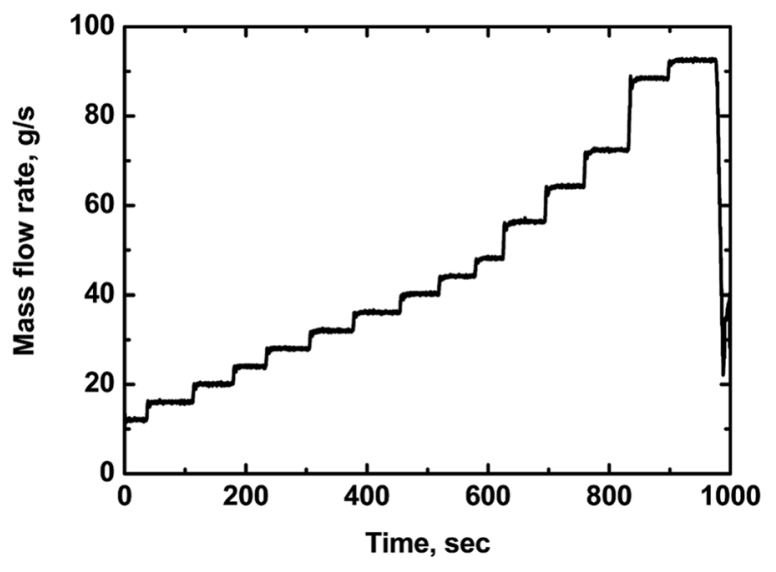

FIG. 14. Time history of the mass flow rate of kerosene.

demonstrates that homogeneity of the heat flux on the test panel is within $\pm 10 \%$.

\section{Mass flow rate of the coolant}

There are two mass flow meters placed in the coolant circulation (Fig. 8). M measures the mass flow rate of the coolant that flows through the test panel, while the other mass flow meter measures the total mass flow rate taking the bypass into account. Their ranges are $0-100 \mathrm{~g} / \mathrm{s}$ and $0-250 \mathrm{~g} / \mathrm{s}$, respectively. In this study, the mass flow rate shown in figures refers to M's reading. With the bypass and two trimming needle valves, namely, V1 and V2, the mass flow rate that flows through the test panel can be regulated conveniently (Fig. 14).

\section{Pressure of the coolant at the outlet}

Pressure is one of the important factors that determine the thermo-physical state of kerosene. Generally, the back pressure is set above the critical point (about $2.4 \mathrm{MPa}$ ) so that overheating caused by boiling can be avoided. Figure 15 shows the process of pressure control in a typical experiment. The back pressure can be varied from 10 bars (subcritical), to 25 bars (near critical), to 50 bars (supercritical).

Figure 16 shows how the nitrogen flow influenced the mass flow rate of the kerosene. In the beginning, the mass flow rate was $35 \mathrm{~g} / \mathrm{s}$, while the pressure of nitrogen's regulator was

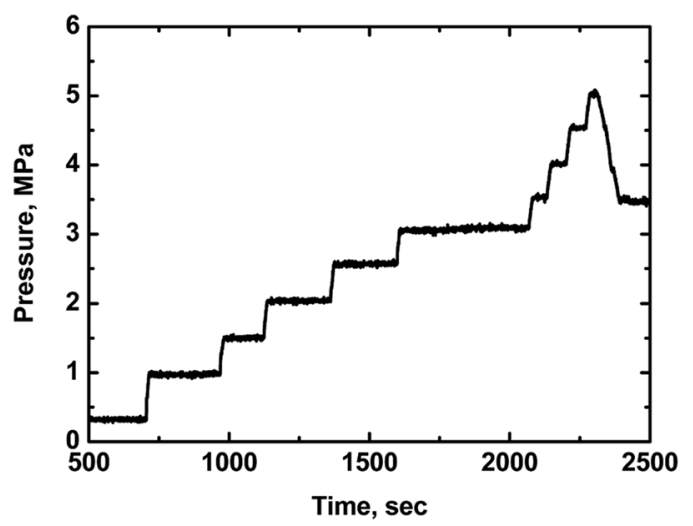

FIG. 15. Time history of the pressure of kerosene at the outlet.

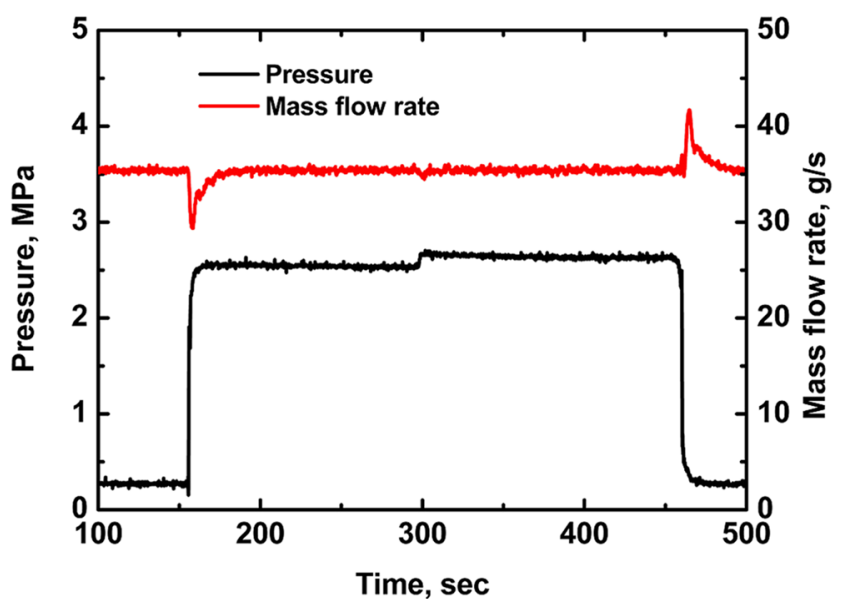

FIG. 16. Time history of the outlet pressure and the mass flow rate of kerosene.

set to be 2.5 MPa. After the needle valve was opened, nitrogen flowed into the main pipe and the exit pressure of the kerosene went up to $2.5 \mathrm{MPa}$ immediately. At the same time, the mass flow rate of kerosene had a sudden decrease of $5 \mathrm{~g} / \mathrm{s}$. Then the feedback control of the plunger pump was activated, and the mass flow rate was raised up to its set value gradually. An inverse process happened when the nitrogen flow was closed. In contrast, micro-adjustment of the pressure at $300 \mathrm{~s}$ did not cause obvious change in the mass flow rate. In the experiments of high heat flux, sudden decrease in the mass flow rate of the coolant is dangerous. Hence, in most experiments, the needle valve was open at the very start and the pressure was regulated continuously.

\section{E. Unique phenomenon in the unilaterally heated test panel with parallel channels}

Figure 17 shows a test panel with rhombic reinforcing ribs and seven mini-channels with cross section of $1.5 \mathrm{~mm}$ $\times 1.5 \mathrm{~mm}$. Thermocouples are welded on the unheated surface of the panel. Two of them are placed at symmetrical locations $A$ and $B$ as shown in the figure. With the symmetrical heat flux on the test panel (Fig. 13), wall temperatures at points A and B should be equal unless the mass flow rates in the channels are distributed asymmetrically. In some cases, the asymmetrical distribution causes drastic oscillation of the total mass flow rate.

As shown in Fig. 18, the total mass flow rate of kerosene in the panel was set to be $35 \mathrm{~g} / \mathrm{s}$. Wall temperatures of points A and $\mathrm{B}$ were equal and increased simultaneously. Then temperature

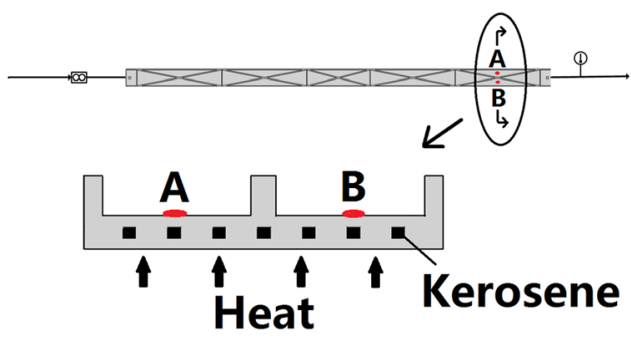

FIG. 17. Configuration of the test panel with 7 mini-channels. 


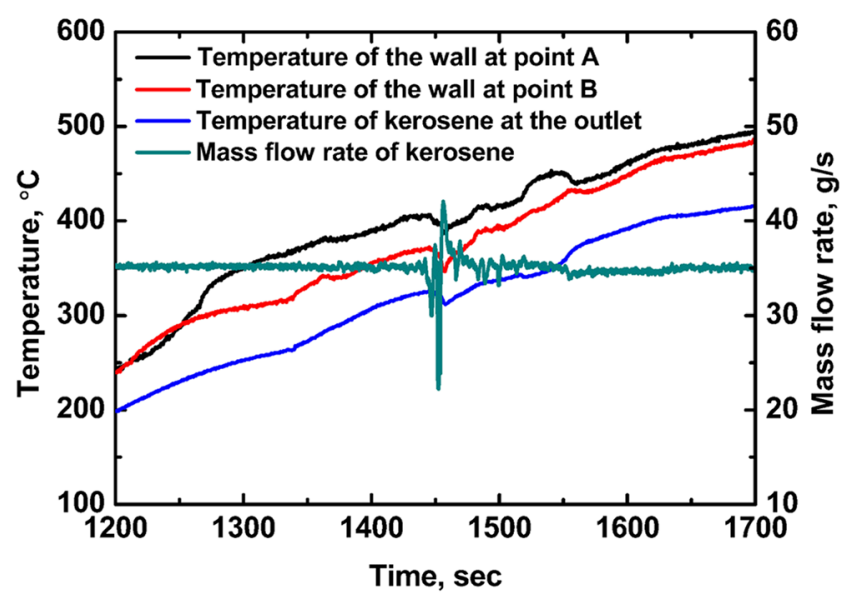

FIG. 18. Time history of the temperatures on the unheated surface of the test panel and the outlet temperature of kerosene and the mass flow rate of kerosene.

of B grew faster and maintained a higher value than that of $\mathrm{A}$ for about $2 \mathrm{~min}$. At $1450 \mathrm{~s}$, oscillation occurred in the mass flow rate and the feedback control was triggered immediately. As the mass flow rate was pulled up, temperatures of both the wall and the kerosene declined. Finally, difference between the temperature of A and B almost vanished and the mass flow rate became stable.

However, even under the PID control, the mass flow rate did not recover in many cases when oscillation occurs. The decrease in the mass flow rate can cause failure of cooling and thermal damage of the test panel, which must be prevented in practical applications. Study of flow instability and heat transfer in active cooling merits further systematic investigation, while the present developed platform laid a sound technical foundation.

\section{CONCLUSIONS}

This study introduced a unilaterally heating facility suitable for simulating the thermal environment between the hot inner flow and the actively cooled wall in a combustion chamber. The facility has the capability of providing an effective heating area of $1000 \mathrm{~mm} \times 40 \mathrm{~mm}$ at the heat flux of over 800 $\mathrm{kW} / \mathrm{m}^{2}$ and handling the coolants of various states. With the precise control of the coolant pressure, this facility will serve as a good platform for studying flow and heat transfer of the hydrocarbons under subcritical, transcritical, or supercritical pressures.

\section{ACKNOWLEDGMENTS}

The research is supported by the Training Program of the Major Research Plan of the National Natural Science Foundation of China (Grant No. 91641110) and National Natural Science Foundation of China (Grant No. 11502270). Tao Yuan, Long Li, Kun $\mathrm{Wu}$, and Lihong Chen are thanked for their exchange of ideas and experience. Ying Li, Jingquan Wang, and Lingjin Meng are thanked for their technique support.

${ }^{1}$ G. P. Sutton, "History of liquid propellant rocket engines in the United States," J. Propul. Power 19(6), 978-1007 (2003).

${ }^{2}$ O. A. Powell, J. T. Edwards, R. B. Norris, K. E. Numbers, and J. A. Pearce, "Development of hydrocarbon-fueled scramjet engines: The hypersonic technology (HyTech) program,” J. Propul. Power 17(6), 1170-1176 (2001).

${ }^{3}$ R. M. Traci, J. L. Farr, Jr., T. Laganelli, and J. Walker, "A thermal management systems model for the NASA GTX RBCC concept," NASA Technical Report, NASA/CR-2002-211587, 2002.

${ }^{4} \mathrm{~T}$. Edwards, "Liquid fuels and propellants for aerospace propulsion: 1903-2003," J. Propul. Power 19(6), 1089-1107 (2003).

${ }^{5}$ X. Fan, G. Yu, J. Li, X. Zhang, and C. J. Sung, "Investigation of vaporized kerosene injection and combustion in a supersonic model combustor," J. Propul. Power 22(1), 103-110 (2005).

${ }^{6}$ Z. Liu, Q. Bi, Y. Guo, J. Yan, and Z. Yang, "Convective heat transfer and pressure drop characteristics of near-critical-pressure hydrocarbon fuel in a minichannel," Appl. Therm. Eng. 51(1-2), 1047-1054 (2013).

${ }^{7}$ D. L. Linne, M. L. Meyer, T. Edwards, and D. A. Eitman, "Evaluation of heat transfer and thermal stability of supercritical JP-7 fuel," AIAA Paper No. 97-3041, 1997.

${ }^{8}$ D. L. Linne, M. L. Meyer, D. C. Braun, and D. J. Keller, "Investigation of instabilities and heat transfer phenomena in supercritical fuels at high heat flux and temperatures," AIAA Paper 2000-3128, 2000.

${ }^{9}$ W. Zhou, B. Yu, J. Qin, and D. Yu, "Mechanism and influencing factors analysis of flowing instability of supercritical endothermic hydrocarbon fuel within a small-scale channel," Appl. Therm. Eng. 71(1), 34-42 (2014).

${ }^{10} \mathrm{G}$. Xia, M. Peng, and Y. Guo, "Research of two-phase flow instability in parallel narrow multi-channel system," Ann. Nucl. Energy 48(48), 1-16 (2012).

${ }^{11}$ Y. Guo, Q. Bi, Z. Liu, Z. Yang, and L. Jiang, "Experimental investigation on thermal-hydraulic characteristics of endothermic hydrocarbon fuel in $1 \mathrm{~mm}$ and $2 \mathrm{~mm}$ diameter mini channels," Appl. Therm. Eng. 122, 420-428 (2017).

${ }^{12}$ M. A. Sillence, "Hydrocarbon scramjet engine technology flowpath component development," AIAA Paper 2002-17-5158, 2002.

${ }^{13}$ X. J. Fan, F. Q. Zhong, G. Yu, J. G. Li, and C. J. Sung, "Catalytic cracking and heat sink capacity of aviation kerosene under supercritical conditions," J. Propul. Power 25(6), 1226-1232 (2009). 